\title{
Morphological and molecular study of Microphallus primas (Digenea: Microphallidae) metacercaria, infecting the shore crab Carcinus maenas from northern Portugal
}

\author{
Susana Pina ${ }^{1}$, Fernanda Russell-Pinto ${ }^{1,2}$ and Pedro Rodrigues ${ }^{3}$ \\ ${ }^{1}$ Laboratory of Aquatic Zoology, ICBAS - Abel Salazar Institute for the Biomedical Sciences, University of Porto, Lg. Prof. Abel \\ Salazar, 2, 4099-003 Porto, Portugal; \\ ${ }^{2}$ CIMAR-CIIMAR - Centre for Marine and Environmental Research, University of Porto, Rua dos Bragas, 289, 4050-123 Porto, \\ Portugal; \\ ${ }^{3}$ Department of Iron Genes and Immune System, IBMC - Institute for Molecular and Cell Biology, Rua do Campo Alegre, 823, \\ 4150-180 Porto, Portugal
}

\begin{abstract}
The present study describes the anatomy and surface topography of the metacercaria of Microphallus primas (Jägerskiöld, 1909) infecting the shore crab Carcinus maenas (L.) in Aveiro estuary, northern Portugal. The metacercaria species identification resulted from the combined use of morphological and molecular data, particularly the 28S rDNA gene. The metacercariae encysted preferentially in the host's hepatopancreas and also in the gonads. Isolated cysts were present in two distinct forms, spherical and oval, and were shown to be the identical species by the internal transcribed spacer 1 (ITS1) sequence. Chemically excysted metacercariae were studied by light (LM) and scanning electron microscopy (SEM). Their specific characteristics observed include the particular aspect of the vesiculo-prostatic pouch surrounded by a very thin membrane, the presence of a prominent muscular papilla, and an obvious metraterm. The dorsal and ventral tegumental surfaces of the metacercaria were densely packed with similar squamous spines, which decreased in number and size towards the hindbody. The edges of the posterior and ventral face of the body were coated with numerous microvilli, whose function remains unknown. In order to identify the species of metacercariae, we compared a $28 \mathrm{~S}$ partial rDNA sequence of the two forms of cysts with the same $28 \mathrm{~S}$ partial region of $M$. primas available in GenBank. With this comparison, we determined that the sequences had a $100 \%$ similarity and therefore belonged to the same species, i.e., M. primas.
\end{abstract}

Keywords: Digenea, Microphallidae, Microphallus primas, ITS1, 28S rDNA, Carcinus maenas, Portugal

The Microphallidae Travassos, 1920 is a large family of small worms whose adults occur as intestinal parasites in most vertebrate classes, but mainly birds. Cercariae have been shown to be produced by sporocysts developing in various prosobranch snails and metacercariae are commonly found in decapod crustaceans (Díaz et al. 2004).

Adult Microphallus primas (Jägerskiöld, 1909) are parasites of the digestive tract of several species of anseriform and charadriiform birds such as Haematopus ostralegus, Somateria mollissima and Larus argentatus, while the metacercariae of the parasite infect the crab Carcinus maenas (L.) (see Deblock and Tran Van Ky 1966, Saville and Irwin 1991). The larval stages (sporocyst and cercaria) develop in a mud snail, Hydrobia ulvae (see Saville and Irwin 1991, 2005). This digenean has recently been recorded as an adult worm in the yellow-legged gull
Larus cachinnans in Galicia, north-west Spain, by Sanmartín et al. (2005).

The use of molecular approaches for the identification of parasites has become commonplace. Generally, complete ITS (internal transcribed spacer) rDNA sequences contain sufficient level of variation to distinguish trematode species clearly, when morphology gives ambiguous results (e.g., Morgan and Blair 1995, Nolan and Cribb 2005). Moreover, the ITS1 region is very useful for investigating intra-specific patterns of variation (Hust et al. 2004). However, some regions are less susceptible to nucleotide changes such as the 28S rDNA, or large subunit rDNA gene (LSU), which is highly conserved. This coding region, together with the $18 \mathrm{~S}$ small subunit rDNA gene (SSU), is widely used to infer deep phylogenetic relationships among ancient lineages (Hillis and Davis 1986).

Address for correspondence: S. Pina, Laboratory of Aquatic Zoology, ICBAS - Abel Salazar Institute for the Biomedical Sciences, University of Porto, Lg. Prof. Abel Salazar, 2, 4099-003 Porto, Portugal. Phone: +351 222062282; Fax: +351 222062232; E-mail: smpina@icbas.up.pt 
The aim of the present study is to describe by light (LM) and scanning electron microscopy (SEM), the anatomy and surface topography of the excysted metacercariae of $M$. primas found infecting the shore crab C. maenas from northern Portugal. As molecular markers, the ITS1 and a partial sequence of the $28 \mathrm{~S}$ rDNA were used to identify the species of the metacercarial stage.

\section{MATERIALS AND METHODS}

\section{Sampling and morphological study of larval stages}

Carcinus maenas were collected at low tide in the São Jacinto channel, Aveiro estuary (Portugal), from February to November 2003. In total, 75 specimens of C. maenas were captured with the aid of a shrimp net, using rotten fish as bait. The crabs were maintained in laboratory aquaria filled with aerated and filtered brackish water from the same location, and were fed with small pieces of frozen fish once a day. Sample specimens were dissected; various organs were removed and pressed between two Petri dishes for cyst detection. Samples of different forms of isolated cysts were observed, photographed and frozen in $50 \mu 1$ of distilled water at $-20^{\circ} \mathrm{C}$ for subsequent DNA analysis. The metacercariae were excysted with a digestive solution. The solution used in the in vitro excystment experiments at $41^{\circ} \mathrm{C}$ for 20 $60 \mathrm{~min}$ was composed of $0.8 \% \mathrm{w} / \mathrm{v} \mathrm{NaCl}, 1.5 \% \mathrm{w} / \mathrm{v} \mathrm{Na} \mathrm{HCO}_{3}$, $0.25 \% \mathrm{w} / \mathrm{v}$ bile salt (sodium taurocholate), $0.25 \% \mathrm{w} / \mathrm{v}$ trypsin, distilled water, $0.02 \mathrm{M} \mathrm{HCl}(\mathrm{pH} 7$ or 8 ), and $0.8 \% \mathrm{w} / \mathrm{v}$ cysteine (adapted from Irwin et al. 1984).

For light microscopy (LM) and scanning electron microscopy (SEM), some metacercariae were processed according to Pina et al. (2009). The description of metacercariae was based on 15 stained and various live specimens.

\section{Histological examination}

For histological examination, the hepatopancreas was removed from the crab and immediately fixed in Bouin's fluid. Following fixation, the samples were dehydrated in a graded ethanol series, cleared with xylene, infiltrated and embedded in paraffin wax, sectioned at 3-5 $\mu \mathrm{m}$ and stained with haematoxylin and eosin (H\&E) using standard protocols.

\section{DNA extraction, PCR amplification and sequencing}

DNA from 68 spherical and 50 oval encysted metacercariae found in naturally infected $C$. maenas was extracted using the GenElute $^{\mathrm{TM}}$ Mammalian Genomic DNA Miniprep Kit (Sigma, St. Louis, Missouri) according to the manufacturer's instructions.

The $18 \mathrm{~S}+\mathrm{ITS} 1+5.8 \mathrm{~S}$ region of the rDNA was amplified using a forward primer located about $195 \mathrm{bp}$ from the 3' end of the conserved region of the SsrDNA (A-ITS1: 5'-GGT AAG TGC AAG TCA TAA GC-3') and a reverse primer located about $35 \mathrm{bp}$ from the 5' end of the 5.8S region (A-ITS1: 5'-GCT GCG CTC TTC ATC GAC A-3') (adapted from Bartoli et al. 2000). Due to the length of ITS1, this region was occasionally amplified using an additional forward primer (N-ITS1: 5'-CGT AAC AAG GTT TCC GTA G-3') located about 23 bp from the 3' end of the $18 \mathrm{~S}$ rDNA.

The 5' start of the $28 \mathrm{~S}$ region was amplified using the primers 28S-F (5'-GTG AAT ACC CGC TGA ACT TAA GC-3') and 28S-R (5'-TCT CCT TGG TCC GTG TTT CAA-3').

Polymerase chain reaction (PCR) was carried out in a total volume of $50 \mu 1$ consisting of $10 \times$ PCR reaction buffer $(200 \mathrm{mM}$
Tris-HCl pH 8.4, $500 \mathrm{mM} \mathrm{KCl),} 0.2 \mathrm{mM}$ dNTP mix, $1.5 \mathrm{mM}$ $\mathrm{MgCl}_{2}, 0.4 \mu \mathrm{M}$ of each primer, $1 \mathrm{U}$ platinum Taq polymerase and $2 \mu 1$ genomic DNA. The cycling conditions were as follows: 1 cycle of initial denaturation at $94^{\circ} \mathrm{C}$ for $5 \mathrm{~min} ; 40$ cycles at $94^{\circ} \mathrm{C}$ for $30 \mathrm{~s}, 54^{\circ} \mathrm{C}$ (or $52{ }^{\circ} \mathrm{C}$ for the $28 \mathrm{~S}$ fragment) for $30 \mathrm{~s}$ and $72^{\circ} \mathrm{C}$ for $2 \mathrm{~min}$; final extension at $72^{\circ} \mathrm{C}$ for $10 \mathrm{~min}$. Samples without DNA were included in each amplification run to ascertain contamination.

Amplified PCR products were analysed by electrophoresis in a 1.0\% agarose gel stained with ethidium bromide, purified with the QIAquick Gel Extraction Kit (Qiagen, Valencia, California) and sequenced. The obtained sequence that included the partial 18S, ITS1 (complete), and partial 5.8S as well as the partial 28S sequence were submitted to GenBank under accession numbers HM001303 and HM001304, respectively.

\section{RESULTS}

Metacercarial cysts of Microphallus primas were found with high prevalence $(96 \%)$ in the hepatopancreas and gonads of Carcinus maenas. A macroscopic examination demonstrated that the heavily infected crabs presented several melanised foci throughout the hepatopancreas. The isolated cysts presented two distinct forms, spherical and oval shape (Fig. 1A, B). The mean diameter of the spherical cysts was $403 \mu \mathrm{m}(394-412)(\mathrm{n}=48)$ and the oval cysts measured $463 \mu \mathrm{m}(338-546)$ long and $357 \mu \mathrm{m}$ (299-427) wide $(n=135)$. In other respects, the different cysts, observed by LM, showed identical characteristics. The metacercariae were folded into a U-shape inside the cysts, and due to their opacity only a few structures were visible, namely the ovary and vitellarium (Fig. 1A, B). The cyst wall was constituted by two layers, the external being thinner than the internal (Fig. 1B). Histological sections also revealed the occasional presence of a thin layer of haemocytes which surrounded the encysted parasites. Around several metacercariae that were at the beginning of the process of encapsulation, a large infiltration of host haemocytes was observed, sometimes including granuloma-like structures (Fig. 2).

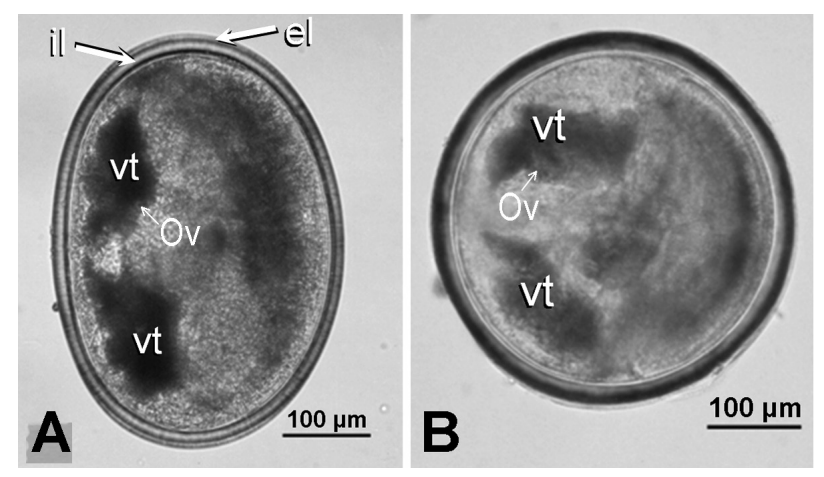

Fig. 1. Photomicrographs of live encysted metacercariae of Microphallus primas isolated from the hepatopancreas of Carcinus maenas. A - oval cyst; B - spherical cyst. Abbreviations: el - external layer; il - internal layer; Ov - ovary; vt - vitellaria. 

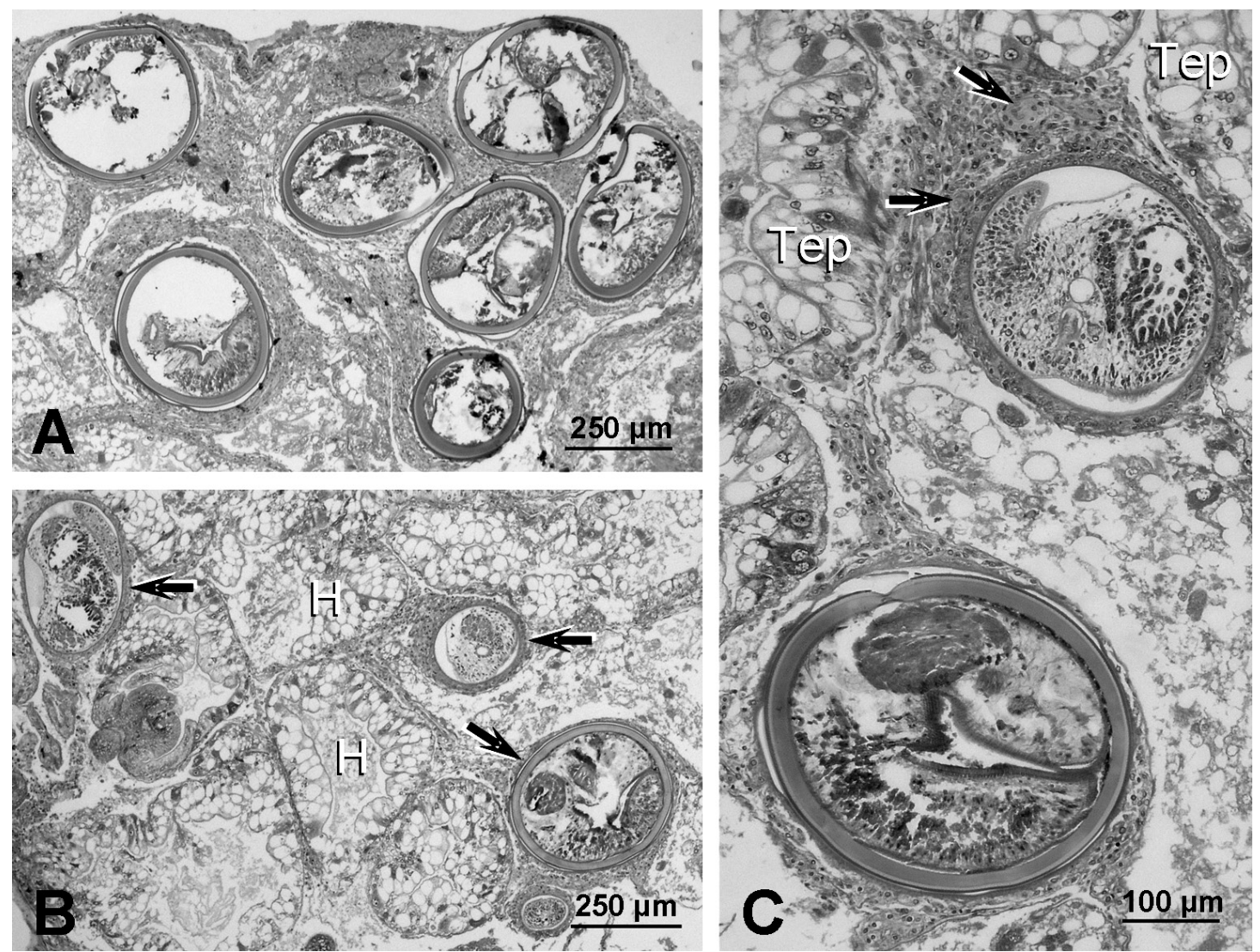

Fig. 2. Photomicrographs of hepatopancreas of Carcinus maenas (paraffin sections stained with H\&E). A, B - metacercarial cysts of Microphallus primas (high infection) (A) at different developmental stages (arrows) (B) displace normal hepatopancreatic tubules (H); C - haemocyte infiltration surrounding a M. primas cyst and apparent granuloma-like formations (arrows); normal tubule epithelial cells (Tep) bound the lesion.

\section{Metacercaria of Microphallus primas}

Description by LM: Excysted metacercaria elongate, pyriform. Oral sucker subterminal, smaller than ventral sucker or acetabulum, which was circular and located at $2 / 3$ of total body length (Fig. 3A). The digestive system consisted of a pre-pharynx, followed by an ovoid pharynx and a straight and very long oesophagus (Fig. 3A, B). Caeca short, divergent, at level of acetabulum (Fig. 3A). Testes 2, symmetrical, postovarian, lateral, elongated, irregular in shape (Fig. 3C). Seminal vesicle antero-sinistral to acetabulum, ovoid. Prostate gland intercaecal, pre-acetabular, large, enveloping seminal vesicle, vas deferens and short ejaculatory duct (Fig. 3D). Vesiculoprostatic pouch delimited by a very thin membrane. Ejaculatory duct short. Male copulatory organ a prominent and muscular papilla (Fig. 3D). Ovary dextral, anterior to testis. Large, dense paired vitelline masses, posterior to testes, composed of about 10 follicles (Fig. 3A, C). Genital atrium closely envelopes male papilla; genital pore sinistral, adjacent to acetabulum. Metraterm long, large, opening into sinistral margin of genital pore (Fig. 3D). Excretory vesicle V-shaped (Fig. 3A). Measurements are given in Table 1.
Table 1. Morphological measurements (mean \pm standard deviation, with the range in parentheses; in $\mu \mathrm{m}$ ) of metacercaria of Microphallus primas.

\begin{tabular}{llcc}
\hline & & This study $(\mathrm{n}=15)$ & Saville and Irwin 1991 \\
\hline Body & length & $934 \pm 87(832-1,040)$ & $725(670-880)$ \\
& width & $487 \pm 26(453-515)$ & $330(265-410)$ \\
Oral sucker & diameter & $56 \pm 9(43-65)$ & $64(50-70)$ \\
Ventral sucker diameter & $89 \pm 5(82-94)$ & $83(80-95)$ \\
Pre-pharynx & length & $58 \pm 13(42-73)$ & $75(70-80)$ \\
Pharynx & length & $27.2 \pm 16.6(2.3-36.4)$ & 40 \\
Ovary & width & $8.4 \pm 13.4(1.3-28.6)$ & 26 \\
& length & $122 \pm 16(104-140)$ & $(120-160)$ \\
Male papilla & width & $156 \pm 14(135-166)$ & nd* \\
& length & $73 \pm 4(66-75)$ & nd \\
Testis left & width & $52 \pm 4(47-56)$ & \\
& length & $95 \pm 15(75-109)$ & length 50 \\
\multicolumn{1}{c}{ right } & width & $159 \pm 14(138-166)$ & width 80 \\
& length & $98 \pm 10(88-109)$ & \\
\hline
\end{tabular}

*nd - not determined. 

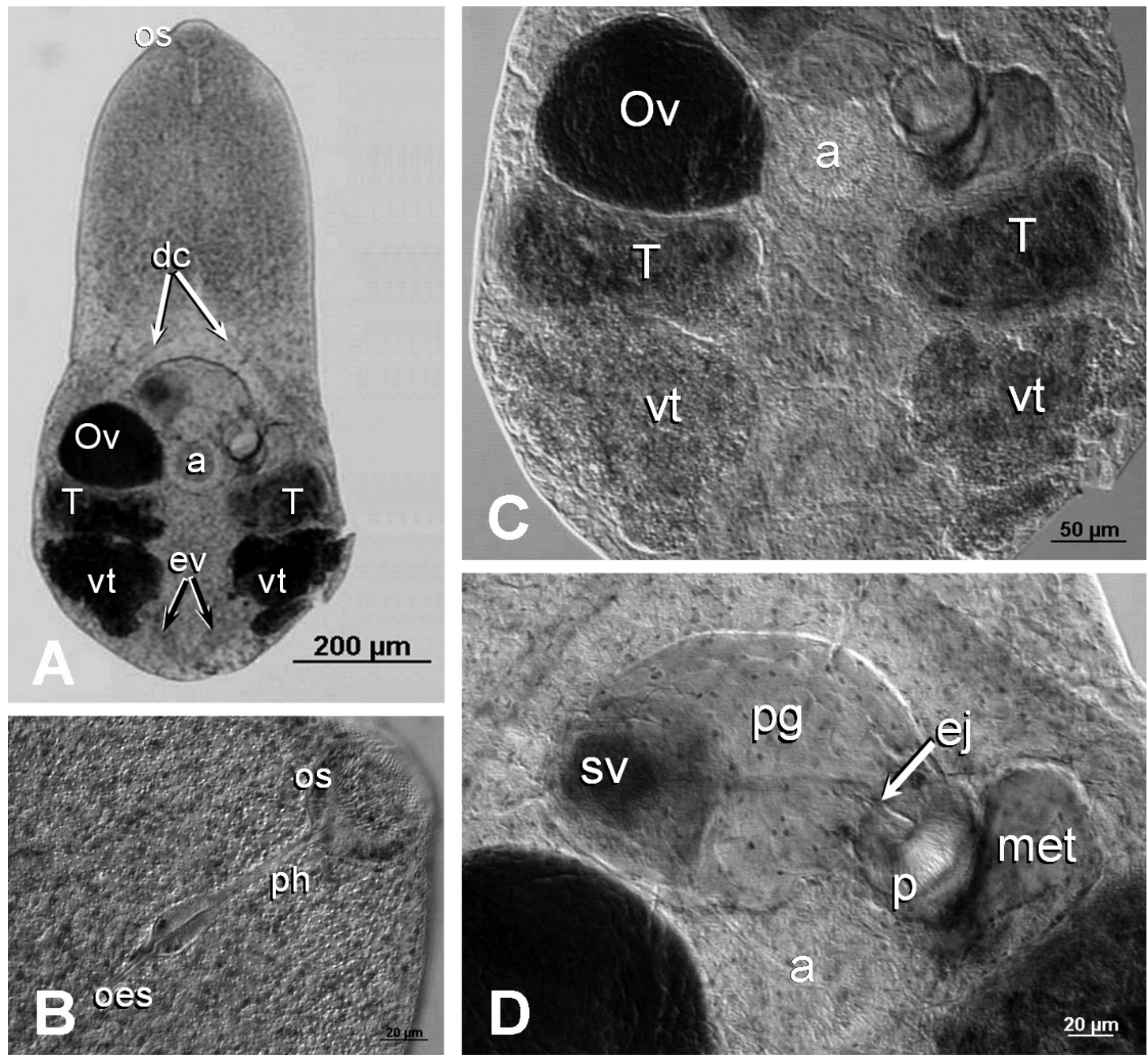

Fig. 3. Photomicrographs of Microphallus primas excysted metacercariae isolated from the hepatopancreas of Carcinus maenas. $\mathbf{A}$ - ventral view; B - high magnification of the cephalic region; $\mathbf{C}$ - detail of the hindbody; $\mathbf{D}$ - high magnification of the middleposterior region. Abbreviations: a - acetabulum; dc - digestive caeca; ej - ejaculatory duct; ev - excretory vesicle; met - metraterm; oes - oesophagus; os - oral sucker; Ov - ovary; $\mathrm{p}$ - papilla; pg - prostate gland; ph - pharynx; sv - seminal vesicle; $\mathrm{T}$ - testes; $\mathrm{vt}-$ vitellaria.

SEM observations: Body pyriform with folded edges (Fig. 4A). Oral sucker subventral, rounded with well defined muscles. Uniciliated sensory papillae 4, on the outer lip of oral sucker, 2 on each side (Fig. 4B). Uniciliated sensory papillae also scattered throughout body surface of metacercaria, more numerous on ventral surface (Fig. 4C). Acetabulum circular, slightly larger than oral sucker (Fig. 4D). Tegument with spines. On forebody numerous large, squamous spines with average 17 teeth on their distal margins (Fig. 4E). Hindbody with small spines and number of teeth per spine gradually decreasing from 4 to 1 antero-posteriorly (Fig. 4F). Transition region between large and small spines clearly defined. Tegument on dorsal and ventral surface not different. Edges of posterior region of ventral face without spines but with numerous microvilli (Fig. 4G, H).
The excysted metacercariae from the two different types of cysts had similar morphology and ultrastructure.

Host: Carcinus maenas (Linnaeus, 1758) (Crustacea, Decapoda) as second intermediate host.

L ocality: S. Jacinto, Ria de Aveiro, North of Portugal $\left(40^{\circ} 30^{\prime} \mathrm{N}, 8^{\circ} 43^{\prime} \mathrm{W}\right)$.

Site of infection: Encysted metacercariae usually located in the hepatopancreas and occasionally in the gonads.

Prevalence: $96 \%$ (72 of 75 C. maenas) for cysts found in the hepatopancreas and $77 \%$ (58 of 75 C. maenas) for cysts found in the gonads, from February to November 2003.

Intensity: The intensity of infection in the hepatopancreas was 504 to 1,125 (mean 949) parasites while in the gonads it ranged from 5 to 11 (mean 7).

Gen Bank Acc. Nos.: HM001303, HM001304. 

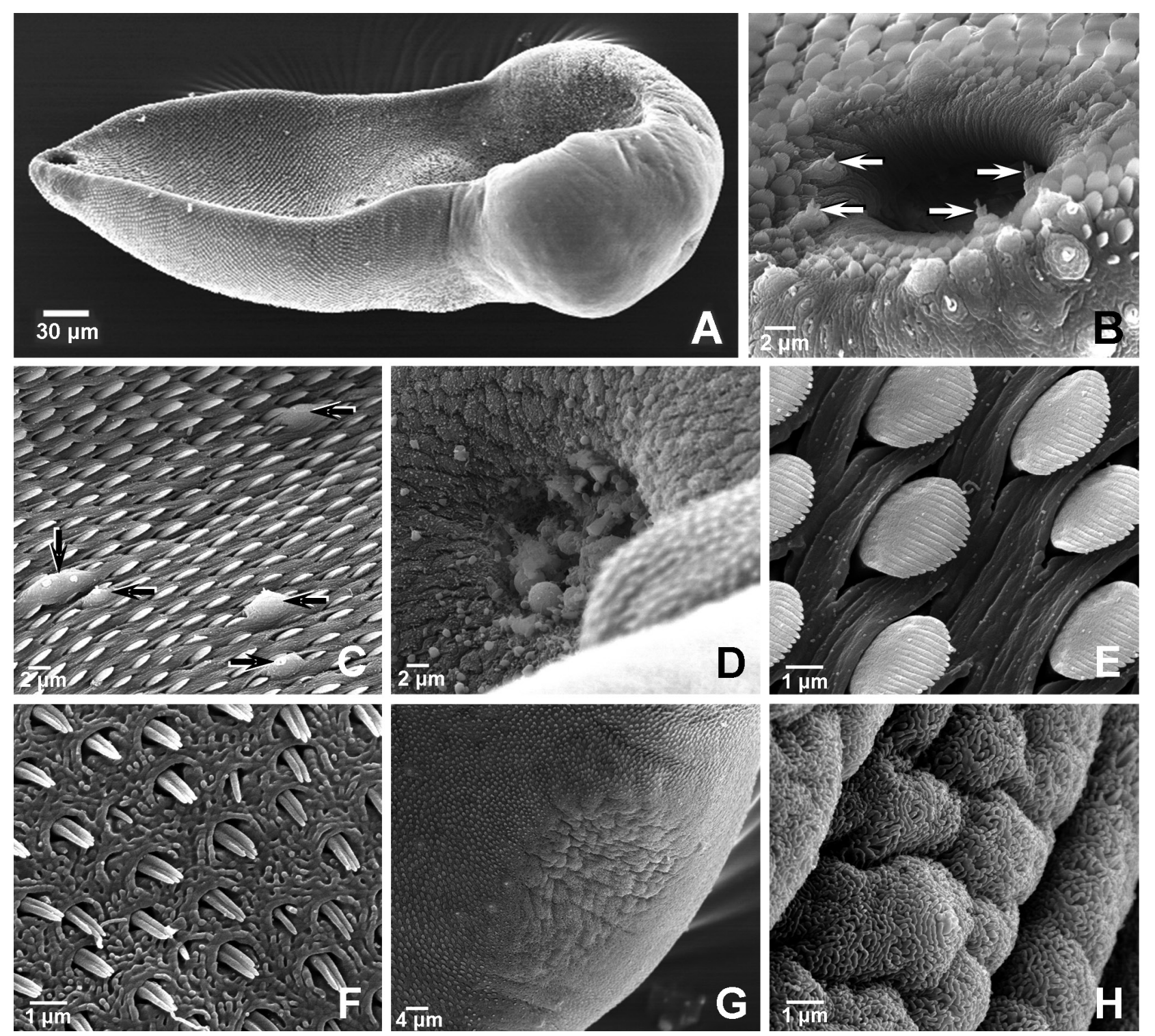

Fig. 4. Scanning electron micrographs of Microphallus primas metacercariae. A - lateral view; $\mathbf{B}$ - oral sucker with four uniciliated sensory papillae on the outer lip (arrows); $\mathbf{C}$ - tegument of the anterior ventral region of the body with uniciliated sensory papillae (arrows); D - ventral sucker or acetabulum; $\mathbf{E}$ - detail of the squamous spines covering the tegument of the forebody; $\mathbf{F}$ - detail of the spined tegument of the hindbody; $\mathbf{G}$ - particular aspect of the edges of the posterior region and ventral face of the body with numerous microvilli; $\mathbf{H}$ - same at higher magnification.

\section{Molecular analysis}

PCR amplification of the $18 \mathrm{~S}+\mathrm{ITS} 1+5.8 \mathrm{~S}$ region of the rDNA from the two different forms of encysted metacercariae gave single products of identical size, 1,373 nucleotides long. After analysis of this PCR product, the first $189 \mathrm{bp}$ were identified as corresponding to the $18 \mathrm{~S}$ gene-coding region. The following $1,151 \mathrm{bp}$ were the ITS 1 sequence and the last $33 \mathrm{bp}$ coded for the ribosomal $5.8 \mathrm{~S}$ unit. For the $28 \mathrm{~S}$ gene, the PCR procedure provided asingle fragment $923 \mathrm{bp}$ long. No identical ITS1 sequence was found in GenBank. However, the BLAST search of the $28 \mathrm{~S}$ partial sequence obtained from this study presented a $100 \%$ similarity to the available $28 \mathrm{~S}$ sequence
AY220627 known from Microphallus primas (Tkach et al. 2003). The ITS1 and 28S sequences obtained from the two forms of encysted metacercariae were identical.

\section{DISCUSSION}

The present study contributes to improve the morphological and ultrastructural characterisation of Microphallus primas metacercaria, a parasite found in the shore crab Carcinus maenas captured from Aveiro estuary, northern Portugal.

The prevalence of $M$. primas infecting crabs was very high and the metacercariae were most commonly found encysted in the hepatopancreas and gonads. The pres- 
ence of melanised foci within hepatopancreas was also observed by Stentiford and Feist (2005), who determined these foci as consisting of metacercariae within an eosinophilic capsule. This encapsulation has been explained as a host immune response and is related to quantitative aspects of the haemocyte recruitment, which vary depending on the parasite size and the type of tissue infected (Martorelli and Schuldt 1990). This explanation is in accordance with our finding of metacercariae in the hepatopancreas of $C$. maenas surrounded by a cyst capsule consisting of a wide internal layer and a thin external layer of haemocytic origin derived from a host reaction.

As far as we could observe, the infection by M. primas did not appear to induce a severe host immune reaction. However, Robaldo et al. (1999) reported that an infection by Microphallus szidati Martorelli, 1986 in another crab species caused structural damage to the hepatopancreas and necrosis of the tubules, altering its glycogen levels.

In this study, the isolated cysts showed two different forms, spherical and oval shape, despite their excysted metacercarie have the same morphological characteristics observed by LM.

It is important to point out that the ovary, testes and vitellaria of the excysted metacercaria were well differentiated under LM. According to Saville and Irwin (1991), in the majority of trematode species that constitute the family Microphallidae, organogenesis occurs within the second intermediate host allowing the parasites to become ovigerous soon after entering the definitive host. The observations of Cable and Hunninen (1940) indicated that the older metacercariae, when removed from the cyst, were practically as large as the adult, which it resembled closely, except that eggs were absent. This progenetic development facilitated the identification of metacercariae since the genital system was almost completely formed (Martorelli and Schuldt 1990). Thus, the metacercarial stage observed in the present work showed the characteristics of $M$. primas by comparison with the descriptions of the adult stage by Yamaguti (1958), Deblock and Tran Van Ky (1966) and Deblock (2008). The specific characteristics observed under LM include the particular aspect of the vesiculo-prostatic pouch, limited by a very thin membrane, the presence of a prominent and muscular papilla, and the presence of an obvious metraterm. According to Deblock and Tran Van Ky (1966) and Deblock (2008) the later structure was heterogeneous, villous proximally and muscular distally.

A comparison of the morphometric data presented in Table 1 revealed that the measurements of the $M$. primas metacercaria described in this study were slightly different from those described by Saville and Irwin (1991). This may be partially explained by the use of different fixation techniques. Moreover, metacercariae can be found at different phases of development in a host, and thus may have different sizes. The $M$. primas observed in the present work had a larger mean body length $(934 \mu \mathrm{m})$ and width $(487 \mu \mathrm{m})$, and testes were nearly double the size reported by Saville and Irwin (1991). Also, the mean length of the pre-pharynx $(58 \mu \mathrm{m})$, as well as the mean dimensions of the pharynx $(27.2 \times 8.4 \mu \mathrm{m})$ were different, when compared with those reported by the same authors $(75 \mu \mathrm{m})$ and $(40 \times 26 \mu \mathrm{m})$ respectively. The dimensions of the male papilla were consistent with those stated by Deblock (1966) to the maximum state of erection.

Among the features observed by SEM we emphasize the presence of numerous squamous spines on the forebody, which gradually decreased in number and size antero-posteriorly. The number of teeth per spine is an important characteristic for distinguishing microphallid species. Comparing the shape and structure of the tegument spines, $M$. primas metacercaria observed in this study had more teeth per spine than M. pygmaeus, M. pseudopygmaeus, $M$. piriformis and $M$. triangulatus, species reported by Galaktionov et al. (2004). According to these authors, the spines of this group of parasites have "evolved to suit their hosts". Thus, M. primas and $M$. piriformis are the species with the highest number of teeth per spine, and those that have been found in gulls and oystercatchers. Contrariwise, the other three species occurring mainly in ducks are those with fewer teeth. Numerous microvilli were observed coating the tegument from the edges of the posterior and ventral face of the body; their function remains unknown but may be directly related to the adhesion of the parasite to the host.

In the present study, the ITS1 sequence of the ribosomal DNA was used to discriminate whether the different forms of cysts isolated from the hepatopancreas of C. maenas belonged to the same species. A match was found between the sequences of the two types of cysts (spherical and oval shape), indicating that they belong to the same species. Since the only available sequences for M. primas in GenBank were the $18 \mathrm{~S}$ and a partial region of the $28 \mathrm{~S}$ rDNA genes, we decided to amplify the same $28 \mathrm{~S}$ region because it shows a faster rate of evolution through its different domains than does the 18S gene (Nolan and Cribb 2005). Thus, from our point of view, the $28 \mathrm{~S}$ gene, despite having very conserved regions, provides a better resolution than the $18 \mathrm{~S}$ gene in the identification of trematode species. The similarity (100\%) found between the $28 \mathrm{~S}$ partial sequence obtained in this study and the $28 \mathrm{~S}$ partial sequence of $M$. primas available in GenBank was expected, as from observations of morpho-anatomic characteristics of the metacercaria we suspected it to be the same species. The $28 \mathrm{~S}$ partial sequence obtained was also the same for the two forms of cysts, indicating that they belong to the same species, i.e. M. primas.

As the morphology alone may be insufficient to unequivocally identify many digenean species, a combination 
with molecular tools allows a quick and accurate identification. Consistent genetic differences that are associated with consistent morphological or biological traits should be considered the marker for separate species (Nolan and Cribb 2005).

In conclusion, this is the first report using a combination of morphological features and molecular data, namely the ITS1 and 28S rDNA genes, that has led to the iden-

\section{REFERENCES}

Bartoli P., Jousson O., Russell-Pinto F. 2000: The life cycle of Monorchis parvus (Digenea: Monorchiidae) demonstrated by developmental and molecular data. J. Parasitol. 86: 479-489.

Cable R.M., Hunninen A.V. 1940: Studies of the life history of Spelotrema nicolli (Trematoda: Microphallidae) with the description of a new microphallid cercaria. Biol. Bull. 78: 136157.

Deblock S. 2008: Family Microphallidae Ward, 1901. In: R.A. Bray, D.I. Gibson and A. Jones (Eds.), Keys to the Trematoda. Vol. 3. CAB International Publishing and The Natural History Museum, London, U.K., pp. 451-492.

Deblock S., Tran VAn Ky P. 1966: Contribution à l'étude des Microphallidae Travassos, 1920 (Trematoda). XII. Espèces d'Europe occidentale. Création de Sphairiotrema nov. gen.; Considérations diverses de systématique. Ann. Parasitol. Hum. Comp. 41: 23-60.

Díaz M.T., Bashirullah A.K., Hernández L.E. 2004: A new species of Microphallus (Trematoda: Microphallidae) from Venezuela. Rev. Biol. Trop. 52: 363-370.

Galaktionov K.V., Bulat S.A., Alekhina I.A., Saville D.H., FitzPatrick S.M., Irwin S.W.B. 2004: Evolutionary relationships within 'pygmaeus' group microphallids using genetic analysis and scanning electron microscopy. J. Helminthol. 78: 231-236.

Hillis D.M., Davis S.K. 1986: Evolution of ribosomal DNA: fifty million years of recorded history in the frog genus Rana. Evolution 40: 1275-1288.

Hust J., Frydenberg J., Sauriau P.-G., Le Gall P., Mouritsen K.N., JENSEN K.T. 2004: Use of ITS rDNA for discriminating of larval stages of two microphallid (Digenea) species using Hydrobia ulvae (Pennant, 1777) and Corophium volutator (Pallas, 1766) as intermediate hosts. Parasitol. Res. 93: 304-310.

Irwin S.W.B., McKerr G., Judge B.C., Moran I. 1984: Studies on metacercarial excystment in Himasthla leptosoma (Trematoda: Echinostomatidae) and newly emerged metacercariae. Int. J. Parasitol. 14: 415-421.

Martorelli S.R., Schuldt M. 1990: Encapsulación de dos metacercarias (Digenea: Microphallidae) en Cyrtograpsus angula-

Received 12 April 2010 tification of $M$. primas metacercaria found infecting the shore crab C. maenas in the northern Portugal.

Acknowledgments. This work was supported through a $\mathrm{PhD}$ grant (SFRH/BD/31767/2006) provided by the FCT - Fundação para a Ciência e a Tecnologia, Ministério da Ciência, Tecnologia e Ensino Superior, Portugal. We would like to thank Dr. Jonathan Wilson (Laboratory of Ecophysiology, CIIMAR) for editing the language of the manuscript.

tus y Palaemonetes argentinus (Crustacea: Decapoda). Rev. Biol. Trop. 38: 295-304.

Morgan J.A.T., BLAIR D. 1995: Nuclear rDNA ITS sequence variation in the trematode genus Echinostoma: an aid to establishing relationships within the 37-collar-spine group. Parasitology 111: 609-615

Nolan M.J., CribB T.H. 2005: The use and implications of ribosomal DNA sequencing for the discrimination of digenean species. Adv. Parasitol. 60: 101-163.

Pina S., Tajdari J., Russell-Pinto F., Rodrigues P. 2009: Morphological and molecular studies on life cycle stages of Diphtherostomum brusinae (Digenea: Zoogonidae) from northern Portugal. J. Helminthol. 83: 321-331.

Robaldo R.B., Monserrat J., Cousin J.C.B., Bianchini A. 1999: Effects of metacercariae (Digenea: Microphallidae) on the hepatopancreas of Chasmagnathus granulate (Decapoda: Grapsidae). Dis. Aquat. Org. 37: 153-157.

Sanmartín M.L., Cordeiro J.A., Álvarez M.F., Leiro J. 2005: Helminth fauna of the yellow-legged gull Larus cachinnans in Galicia, north-west Spain. J. Helminthol. 79: 361-371.

Saville D.H., Irwin S.W.B. 1991: In ovo cultivation of Microphallus primas (Trematoda: Microphallidae) metacercariae to ovigerous adults and the establishment of the life-cycle in the laboratory. Parasitology 103: 479-484.

SAVIlle D.H., Irwin S.W.B. 2005: A study of the mechanisms by which the cercariae of Microphallus primas (Jag, 1909) Stunkard, 1957 penetrate the shore crab, Carcinus maenas (L). Parasitology 131: 521-529.

Stentiford G.D., Feist S.W. 2005: A histopathological survey of shore crab (Carcinus maenas) and brown shrimp (Crangon crangon) from six estuaries in the United Kingdom. J. Invertebr. Pathol. 88: 136-146.

Tkach V.V., Littlewood D.T.J., Olson P.D., Kinsella J.M., Swiderski Z. 2003: Molecular phylogenetic analysis of the Microphalloidea Ward, 1901 (Trematoda: Digenea). Syst. Parasitol. 56: 1-15.

Yamaguti S. 1958: Systema Helminthum. Vol. I. The Digenetic Trematodes of Vertebrates - Part I. Interscience Publishers Inc., New York, 979 pp.

Accepted 3 September 2010 